\title{
Comparative Study of the Protective Effect of Granulated Sugar and Garri Meal on Petroleum-induced Changes of Lipid Profiles in Albino Rats (Rattusnorvegicus)
}

\section{${ }^{* 1}$ ADEGOKE, O. ADEBAYO; ${ }^{2}$ BAMIGBOWU, E. OLUGBENGA; ${ }^{3}$ GEORGE-OPUDA M. IBITOROKO; ${ }^{4}$ BRAIDE, A. SOLOMON; ${ }^{5}$ OKEKE, U. CHUKWUEBUIKE; ${ }^{6}$ EKWUSA V. OBIAGERI}

\author{
(1) Department of Medical Laboratory Science, Madonna University, Elele,Nigeria \\ E-mail bayoadeghq@yahoo.com.Tel+2348037103687 \\ (2) Department of Chemical Pathology, College of health science, University of Port Harcourt, Port Harcourt. \\ E-mail eogbenga@yahoo.com, Tel+2348033380957 \\ (3) Department of Medical Laboratory Science, Rivers State University of Science and Technology, Port Harcourt \\ E-mailibitorokogeorge@yahoo.com Tel+2348033426056 \\ (4) Institute of Pollution Studies, Rivers State University of Science and Technology, Port Harcourt \\ E-mail sabraide@hotmail.com.Tel+2348023124938 \\ (5) Department of Prosthesis and Orthopaedic technology, Federal University of Technology, Owerri Imo state \\ E-mail jer32vs27@yahoo.com,\& jindsph@yahoo.com.Tel+2348037353551 \\ (6) School of Medical Laboratory Science, University of Port Harcourt teaching hospital, Port Harcourt.
}

\begin{abstract}
Crude oil contaminated diet has been reported to induced changes in lipid profile of rats. In this study, 60 albino rats in 6 groups were fed with crude oil contaminated sugar-garri diets at varied concentrations to monitor petroleum-induce lipid profile changes using standard methods. The lipid profiles estimated were total cholesterols, triglycerides, high density lipoprotein cholesterol and Low density lipoproteincholesterol.The data showed that, the levels of total cholesterol $(\mathrm{Mmol} / \mathrm{l})$ increased from $2.89 \pm 0.08$ in sugar fed rats compared with $3.05 \pm 0.12$ in Gari fed rats. The concentration of triglycerides(Mmol/l) reduced from $1.10 \pm 0.51$ in sugar fed rats to $1.06 \pm 0.03$ in Gari fed rats while the high density lipoprotein cholesterol(Mmol/l) concentration of 2 . $01 \pm 0.08$ was significantly higher than $1.89 \pm 0.03$ in Gari fed rats $(\mathrm{P}<0.05)$. There was no significant difference in Low density lipoprotein cholesterol $(\mathrm{Mmol} / \mathrm{l})$ concentrations of $0.68 \pm 0.11$ in sugar fed rats compared with $0.83 \pm 0.10$ in Gari fed rats. The effect of pre-treatment of the diet with sugar reduced petroleum-induce changes in lipid profile than gari during the exposure of the albino rats to the petroleum diet suggesting that sugarcould possibly ameliorate petroleum-induce changes in lipid profile as shown by the significantlowering of the cholesterol and Low density lipoprotein cholesterol than gari in albino rats. ( JASEM https://dx.doi.org/10.4314/jasem.v21i2.12
\end{abstract}

Keywords: lipid, Petroleum, Sugar, Gari, Cassava, Changes

Crude oil has been described as a complex mixture of over 6000 potentially different hydrocarbons and metal (Edwards, 1989) and the chemical composition varies between geologic formations (Coppock et al.,1995). Exposure of humans and animal to crude oil, which is increasing in terms of the environmental levels, and application to body, may be toxic. Crude oil is used in folkloric medicine in the Niger-delta area of Nigeria for the treatment of various ailments including stomach up-set, wound, and burns (Orisakwe, et al., 2000). The route of administration is mostly oral and external application for burns and wounds. The ingestion of petroleum hydrocarbon has been reported to induce oxidative stress ( $\mathrm{Val}$ and Almeida-Val, 1999) through the generation of free radical (Achuba and Osakwe, 2003). It has been established that free radical generation with subsequent oxidative modification leads to lipid peroxidation (Halliwell, 1994) that damages critical cellular macromolecules such as DNA, lipids and proteins (Breimer 1990; Romero et al 1998; Souza et al, 1999); that results in inactivation of antioxidant enzymes (Pigeolet et al., 1990). Hydrocarbons and other constituents of petroleum and petrochemical products like other xenobiotics are metabolized in the liver to a greater extent (Sims, 1980). Achuba (2005) had reported that total cholesterol and LDLcholesterol were insignificantly increased while HDL-cholesterol and triglyceride significantly decreased in rabbits fed petroleum contaminated diet and the ingestion of crude petroleum contaminated diet imposed a reciprocal relationship between HDLcholesterol and LDL-cholesterol in the plasma of Rabbit. Nearly all of the energy needed by the human body is provided by the oxidation of carbohydrates and lipids. 
The sugar cane is one of the most important sucrose sources, containing until $20 \%$ weight sucrose (Glazer and Nikaido, 1995). Sucrose hydrolysis produces a fructose and glucose equimolar mixture named inverted sugar, which has higher edulcorant power. The inverted sugar is incorporated more easily in industrial preparations and has more added value than sucrose (Chou and Jasovsky 1993). Sugar has been reported to reduce haematoxicity caused by petroleum (Braide et al., 2011a).

Cassava was transplanted from Brazil to Africa by the Portuguese nearly three centuries ago (Bourdoux et al., 1980). Gari processing consisted of peeling, shredding, fermenting and dehydrating (light roasting) in sacks for 3-4 d, sifting, gelatinizing and roasting. Gari is made by grating cassava (Mannihot esculenta Crantz) and then dehydrating the fibre in sacks for 3 days after which the residue is roasted. Cassava is a staple food in human diets in over 80 countries (Gomez et al., 1988). Gari a starchy food prepared from cassava (Mannihot esculenta Crantz)tubers is one of the most popular staple foods of the people of the rain forest belt of West Africa and contains mainly starch-20\% amylase and $70 \%$ amylopectin having lost the soluble carbohydrates (i.e. glucose and sugar) during processing. Gari has been reported to reduce enzymes induction caused by petroleum through the phenomenon of glucose effect (Braide et al., 2011b).

The aim of this paper was to compare possible protective roles of sugar and gari diets against petroleum induced changes in lipids using cholesterol, triglycerides, high density lipoprotein cholesterol and Low density lipoproteincholesterol as indicators.

\section{MATERIAL AND METHODS}

Experimental animals: Sixty Wistar albino rats of $0.195 \mathrm{~kg}$ average body weight on normal rat diet were obtained from the animal house of the department of Pharmacology and Toxicology, University of Port Harcourt. These rats were fed adlibitum with normal rat pellet and water and acclimatized to laboratory conditions for a period of 14days prior to commencement of study. The gari and sugar used in this study was purchased from Mile 3 Market, Port Harcourt. The crude petroleum used (Bonny Light) was obtained from the Nigerian National Petroleum Corporation (N.N.P.C.) Zonal Office at Moscow Road, Port Harcourt. Commercially prepared Cholesterol, triglycerides, and HDL precipitant were obtained from Randox Diagnostics, London
Animal studies: Preliminary study was carried out by authors to ascertain the sugar and gari concentrations that will cause glucose effect by feeding rats with various concentrations of sugar and gari, then observing the concentration of sugar and gari with the lowest cholesterols concentration. The albino rats were fed contaminated diet mixed with $20 \%$ sugar and $20 \%$ gari adlibitum for three weeks, slaughtered and blood samples taken for analysis. The concentrations of crude oil used were 3.88, 7.75, $15.51,31.01$ and $62.02 \mathrm{~g} / \mathrm{kg}$ while the last group was fed rat diet with distilled water adlibitum to serve as control. Preliminary investigation had established that this concentration of crude oil was tolerable to the albino rats on a prolonged basis without any drastic effect.

Biochemicalstudies: The cholesterol is determined after enzymatic hydrolysis and oxidation. The indicator quinoneimine is formed from hydrogen peroxide and 4-aminoantipyrine in the presence of phenol and peroxides (Allainet al 1974).

Ten microlitre (10 $\mu l$ ) of sample, control, standard and distilled water was pipette into respective test tube then $1000 \mu l$ of cholesterol working reagent was added. It was mixed and incubated for 5 minutes at $37^{\circ} \mathrm{C}$. The absorbance of the sample was measured against the reagent blank at $520 \mathrm{~nm}$. The concentration of sample was calculated using the absorbance of sample against absorbance of standard multiplied by concentration of standard.

The triglycerides are determined after enzymatic hydrolysis with lipases. The indicator is a quinoneimine formed from hydrogen peroxide, 4aminophenazone and 4-chlorophenol under the catalytic influence of peroxidase (Buccolo and David 1973).

Ten microlitre (10) $\mu l$ of sample, control, standard and distilled water was pipetted into respective test tube then $1000 \mu l$ of triglyceride reagent was added. It was mixed and incubated for 5 minutes at $37^{\circ} \mathrm{C}$. The absorbance of the sample was measured against the reagent blank at 520nm. The concentration of sample was calculated using the absorbance of sample against absorbance of standard multiplied by concentration of standard.

Low density lipoproteins (LDL and VLDL) and chylomicron fractions are precipitated quantitatively by the addition of phosphotungstic in the presence of magnesium ions. After centrifugation, the cholesterol 
concentration in the HDL (high density lipoprotein) fraction, which remains in the supernatant, was determined.

Five hundred (500) $\mu l$ of sample, control standard and distilled water was added into respective test tubes, $1000 \mu l$ of precipitant was added into all the tubes. It was mixed and allowed to stand for 10 minutes at room temperature. It was centrifuged for 2 minutes at $12,000 \mathrm{rpm}$. Then $10 \mu l$ of supernatant from control, standard and distilled water was added into their respective test tubes and cholesterol concentration of supernatant was determined as shown above by method of Allain et al (1974).

LDL-cholesterol was calculated using the formula of Friedwald et al (1972) as shown below

LDL-cholesterol $(\mathrm{Mmol} / \mathrm{L}) \quad=$ Total cholesterol $(\mathrm{Mmol} / \mathrm{L})-(\mathrm{HDLC}(\mathrm{Mmol} / \mathrm{L})+\mathrm{TG} / 2.22)(\mathrm{Mmol} / \mathrm{L})$.

Statistical analysis: The biochemical data were subjected to some statistical analysis. Values were reported as Mean \pm SEM while student's t-test was used to test for differences between treatment groups using Statistical Package for Social Sciences (SPSS) version 16.A value of $\mathrm{P}<0.05$ was accepted as significant.

\section{RESULTS AND DISCUSSION}

The cholesterol concentration for control in sugar treated albino rats was $1.64 \pm 0.29$. At $3.88 \mathrm{~g} / \mathrm{kg}$ of sugar treatment, concentration was $2.64 \pm 0.22$, while it increased to $2.74 \pm 0.24,2.92 \pm 0.16,3.06 \pm 0.15$ and $3.09 \pm 0.96$ at concentrations of $7.75,15.51$, 31.01 and $62.02 \mathrm{~g} / \mathrm{kg}$ respectively. The Cholesterol concentration $(\mathrm{Mmol} / \mathrm{L})$ of the control in gari treated albino rats was $2.62 \pm 0.17$. At $3.88 \mathrm{~g} / \mathrm{kg}$ of gari treatment, the concentration was $2.64 \pm 0.29$, while it increased to $3.11+0.11,3.13+0.28,3.15+0.28$ and $3.22+0.36$ at concentrations of $7.75,15.51,31.01$ and $62.02 \mathrm{~g} / \mathrm{kg}$ respectively as shown below in table 1. One of the major problems of the inhabitants of the Niger Delta region of Nigeria is contamination of water and aquatic lives by crude oil. This contamination may not necessarily lead to outright mortality but may have significant effects which can lead to physiological stress and dysfunction in animals (Omoregie, 1998).The result showed a reduction in cholesterol concentration of sugar fed compared with gari fed. This suggests that feeding on $20 \%$ sugar tend to reduce cholesterol in petroleum treated rats than gari treated rats. Achuba (2005) had reported that feeding rabbits with diets containing various concentrations of crude petroleum caused significant dose related increases in cholesterol suggesting that ingestion of petroleum contaminated diet could predispose humans to cardiovascular diseases while the result of this study has shown that sugar diet reduced cholesterol concentration more than gari diet. Adegoke et al. (2013) reported that feeding sugar and gari can cause synthesis of total and HDL cholesterols but the increase is more pronounced in gari than sugar. Braide et al (2011c) in their study reported that sugar diet reduced enzymes induction in petroleum treated rats more than gari. This was attributed to cyanogenic component present in gari. Ezeji et al (2009) had suggested that cyanide affects some important enzymes of the mitochondtrial electron transport system which are used as markers of the organelle.

The triglyceride concentration of $1.38 \pm 0.11$ was obtained in the control of sugar treated albino rats which reduced to $1.28 \pm 0.20$ at $3.88 \mathrm{~g} / \mathrm{kg}$. The concentration further decreased to $1.15 \pm 0.01$, $1.03 \pm 0.16, \quad 1.03 \pm 0.03$ and $1.01 \pm 0.01$ at concentrations of $7.75,15.51,31.01$ and $62.02 \mathrm{~g} / \mathrm{kg}$ respectively. The triglyceride $(\mathrm{Mmol} / \mathrm{L})$ of $1.34 \pm 0.11$ was obtained in the control of gari treated albino rats which reduced to $1.25 \pm 0.04$ at $3.88 \mathrm{~g} / \mathrm{kg}$. The concentrations further increased to $1.06 \pm 0.03$, $1.03 \pm 0.01, \quad 1.02 \pm 0.07$ and $0.96 \pm 0.02$ at concentrations of $7.75,15.51,31.01$ and $62.02 \mathrm{~g} / \mathrm{kg}$ respectively as shown below in table 1. Achuba (2005) reported significantly decreased triglyceride in rabbits fed petroleum contaminated diet but the result of this study showed that sugar fed rats increased triglycerides more than the gari fed rats. In humans, hypertriglyceridemia can be induced endogenously by a high fat diet (Austin et al., 1998) or it can be carbohydrate induced (Knittle and Ahrens 1964, Reavenet al 1965). A high triacylglycerol (TAG) flux rate was observed in subjects fed HCLF diet (Abbott, et al., 1990). The TAG increase observed in humans on a HCLF diet may have been from de novo lipogenesis (Parks, and Hellerstein 2000). Ben-David et al (2001) reported that the ingestion of petroleum caused reduction in blood glucose causing shift in the demand for metabolic substrate to lipid, the supplementation of the diet with sugar and gari reversed the reduction in blood glucose hence the shift in demand for lipid will be reversed causing increase triglycerides. The increase in triglycerides concentrations of sugar more than gari might be as a result of some other components like cyanogens present in gari. 
Table 1 Effect of Gari and Sugar on cholesterol and triglycerides in albino rats treated with petroleum

\begin{tabular}{cllllll}
\hline & \multicolumn{3}{l}{ CHOLESTEROL $(\mathrm{Mmol} / \mathrm{L})$} & \multicolumn{3}{l}{ TRIGLYCERIDES $(\mathrm{Mmol} / \mathrm{L})$} \\
\hline CONCENTRATION & SUGAR & GARI & P VALUE & SUGAR & GARI & P VALUE \\
$(\mathrm{g} / \mathrm{kg})$ & TREATED & TREATED & & TREATED & TREATED & \\
0.00 & $2.64 \pm 0.29$ & $2.62 \pm 0.17$ & 0.337 & $1.38 \pm 0.11$ & $1.34 \pm 0.11$ & 0.911 \\
3.88 & $2.64 \pm 0.22$ & $2.64 \pm 0.29$ & 0.473 & $1.28 \pm 0.20$ & $1.25 \pm 0.04$ & 0.703 \\
7.75 & $2.74 \pm 0.24$ & $3.11 \pm 0.11$ & 0.006 & $1.15 \pm 0.01$ & $1.06 \pm 0.03$ & 0.163 \\
15.51 & $2.92 \pm 0.16$ & $3.13 \pm 0.28$ & 0.006 & $1.03 \pm 0.16$ & $1.03 \pm 0.01$ & 0.473 \\
31.01 & $3.06 \pm 0.15$ & $3.15 \pm 0.28$ & 0.163 & $1.03 \pm 0.03$ & $1.02 \pm 0.07$ & 0.473 \\
62.02 & $3.09 \pm 0.96$ & $3.22 \pm 0.36$ & 0.703 & $1.01 \pm 0.01$ & $0.96 \pm 0.02$ & 0.275 \\
\hline
\end{tabular}

The HDL cholesterol concentration for control in sugar treated albino rats was $2.46 \pm 0.03$ at $3.88 \mathrm{~g} / \mathrm{kg}$ of sugar treatment; concentration was $2.30 \pm 0.08$, while it reduced to $2.07 \pm 0.02,1.90 \pm 0.03,1.91$ +0.03 and $1.88+0.03$ at concentrations of 7.75 , $15.51,31.01$ and $62.02 \mathrm{~g} / \mathrm{kg}$ respectively. The HDL Cholesterol concentration $(\mathrm{Mmol} / \mathrm{L})$ of the control in gari treated albino rats was $2.42 \pm 020$. At $3.88 \mathrm{~g} / \mathrm{kg}$ of gari treatment, the concentration was $2.08 \pm 0.10$, while it decreased to $1.84 \pm 0.01,1.88 \pm 0.01,1.82$ \pm 0.02 and $1.81 \pm 0.04$ at concentrations of 7.75 , $15.51,31.01$ and $62.02 \mathrm{~g} / \mathrm{kg}$ respectively as shown below in table 2 . The LDL cholesterol concentration for control in sugar treated albino rats was $1.46 \pm$ 0.14 . At $3.88 \mathrm{~g} / \mathrm{kg}$ of sugar treatment, concentration was $1.06 \pm 0.37$, while it reduced to $0.40 \pm 0.15,0.60$ $\pm 0.05,0.62+0.18$ and $0.73 \pm 0.11$ at concentrations of $7.75,15.51,31.01$ and $62.02 \mathrm{~g} / \mathrm{kg}$ respectively. The LDL Cholesterol concentration (Mmol/L) of the control in gari treated albino rats was $1.25 \pm 0.33$. At $3.88 \mathrm{~g} / \mathrm{kg}$ of gari treatment, the concentration was
$0.58 \pm 0.17$, while it increased to $0.61 \pm 0.10,0.74 \pm$ $0.30,0.94+0.16$ and $1.28 \pm 0.25$ at concentrations of $7.75,15.51,31.01$ and $\overline{6} 2.02 \mathrm{~g} / \mathrm{kg}$ respectively as shown below in table 2 . This study reported an increase HDL cholesterol with reduction in LDL cholesterol concentrations of sugar fed albino rats compared to gari fed rats suggesting that sugar diets increases good cholesterol as HDL is known while reducing the LDL cholesterol than gari diet. Achuba (2005) had reported that the ingestion of crude petroleum contaminated diet imposed a reciprocal relationship between HDL-cholesterol and LDLcholesterol in the plasma of Rabbit. The decrease in HDL-cholesterol with a corresponding increase in LDL- cholesterol is the primary risk factor for coronary heart disease (Mckee and Mckee, 1999, Glew, 1997). Achuba (2005) reported that supplementation of diet with vitamins $\mathrm{E}$ and $\mathrm{C}$ could possibly ameliorate petroleum-induce changes in lipid profile while vitamin $\mathrm{E}$ appeared more effective than vitamin $\mathrm{C}$

Table 2 Effects of gari and sugar on HDL cholesterol and LDL cholesterol in albino rats treated with petroleum

\begin{tabular}{cllllll}
\hline & \multicolumn{2}{l}{ HDL CHOLESTEROL $(\mathrm{Mmol} / \mathrm{L})$} & \multicolumn{3}{l}{ LDL CHOLESTEROL $(\mathrm{Mmol} / \mathrm{L})$} \\
\hline CONCENTRATION & SUGAR & GARI & P VALUE & SUGAR & GARI & P VALUE \\
$(\mathrm{g} / \mathrm{kg})$ & TREATED & TREATED & & TREATED & TREATED & \\
0.00 & $2.46 \pm 0.03$ & $2.42 \pm 0.20$ & 0.862 & $1.46 \pm 0.14$ & $1.25 \pm 0.33$ & 0.911 \\
3.88 & $2.30 \pm 0.08$ & $2.08 \pm 0.10$ & 0.911 & $1.06 \pm 0.37$ & $0.58 \pm 0.17$ & 0.044 \\
7.75 & $2.07 \pm 0.02$ & $1.84 \pm 0.01$ & 0.401 & $0.40 \pm 0.15$ & $0.61 \pm 0.10$ & 0.980 \\
15.51 & $1.90 \pm 0.03$ & $1.88 \pm 0.01$ & 0.05 & $0.60 \pm 0.05$ & $0.74 \pm 0.30$ & 0.401 \\
31.01 & $1.91 \pm 0.03$ & $1.82 \pm 0.02$ & 0.05 & $0.62 \pm 0.18$ & $0.94 \pm 0.16$ & 0.499 \\
62.02 & $1.88 \pm 0.03$ & $1.81 \pm 0.04$ & 0.05 & $0.73 \pm 0.11$ & $1.28 \pm 0.25$ & 0.674 \\
\hline
\end{tabular}

There was significant lowering of cholesterol concentration $(\mathrm{Mmol} / \mathrm{L})$ in sugar treated albino rats with $2.89 \pm 0.08$ compared with $3.05 \pm 0.12$ of gari fed rats. Triglyceride $(\mathrm{Mmol} / \mathrm{L})$ concentration was increased from $1.10 \pm 0.51$ in sugar treated rats compared with $1.06 \pm 0.03$ in gari treated rats. The HDL Cholesterol (Mmol/L) concentration of $1.89 \pm$ 0.03 in gari treated rats was significantly lower than $2.01 \pm 0.08$ in sugar treated albino rats. The LDL cholesterol $(\mathrm{Mmol} / \mathrm{L})$ of $0.83 \pm 0.10$ in gari treated rats was significantly different from $0.68 \pm 0.11$ in sugar treated rats as shown below in table 3. Braideet al., (2013) in their study reported that ingestion of petroleum contaminated diet caused increase cholesterol and LDL cholesterol and decreased triglycerides and HDL cholesterol while feeding on gari diet caused reversed to changes in lipid concentration caused by crude petroleum. Also Adegoke et al., (2012) reported that ingestion of petroleum contaminated diet caused decreased haemoglobin $(\mathrm{Hb})$, Packed cell volume (PCV) and white blood cell count (an indicator of possible blood damage) but supplementation of the diet with $20 \%$ gari further decreased the haemoglobin $(\mathrm{Hb})$, Packed cell volume (PCV) and white blood cell count observed in petroleum fed albino rats. Therefore, this study has shown that sugar diet appeared to ameliorate petroleum-induced changes in lipid profile compared with gari. This may as a result of 
cyanogens present in gari which is absent in granulated sugar used in this study.

Table 3 effect of Sugar and Gari on lipid concentration in albino rats treated with petroleum

\begin{tabular}{llll}
\hline Parameter $(\mathbf{M m o l} / \mathbf{L})$ & Sugar & Gari & P value \\
\hline Cholesterol & $2.89 \pm 0.08$ & $3.05 \pm 0.12$ & 0.063 \\
Triglycerides & $1.10 \pm 0.51$ & $1.06 \pm 0.03$ & 0.088 \\
HDL Cholesterol & $2.01 \pm 0.08$ & $1.89 \pm 0.03$ & 0.040 \\
LDL Cholesterol & $0.68 \pm 0.11$ & $0.83 \pm 0.10$ & 0.437 \\
\hline
\end{tabular}

Conclusion:This study has shown that sugar diet appeared to ameliorate petroleum-induced changes in lipid profile compared with gari. The effect of pretreatment of the diet with sugar reduced petroleuminduce changes in lipid profile than gari during the exposure of the albino rats to the petroleum diet suggesting that sugar could possibly ameliorate petroleum-induce changes in lipid profile as shown by the significant lowering of the cholesterol and Low density lipoprotein cholesterol than gari in albino rats.

Acknowledgement: The authors are grateful to Management of Sigma laboratories, Port Harcourt for the biochemical analysis and Mr Enyaosa Tony for his help in the literature review.

\section{REFERENCES}

Abbott, WGH; Swinburn, B; Ruotolo G; Hará H; Patti L; Harper, I; Grundy, SM; Howard BV.(1990). Effect of a high carbohydrate, lowsaturated-fat diet on apolipoprotein B and triglyceride metabolism in Pima Indians. Journal of Clinical Investigation, 86: 642-50.

Achuba, FI(2005). Effect of vitamins C and E intake on blood lipid Concentration, lipid peroxidation, superoxide dismutase and catalase activities in Rabbit fed petroleum contaminated diet. European Journal of Scientific Research,12 (1): 20-28.

Achuba, FI;Osakwe SA. (2003). Petroleum induced free radical toxicity in African catfish (Clariasgariepinus) Fish Physiology Biochemistry 29(2):97-103.

Adegoke, OA; Bamigbowu, OE; George- Opuda, MI; Okeke, UC; Mbata CA; Nwagu. C. (2013).Effect of Granulated Sugar And Gari Feed Diet On Lipid Profile In Albino Rats (Rattus norvegicus) International Journal of Applied Biological Research 5(1): 20 - 32
Ahrens, EHJnr; Hirsch, J;Oette, K; Farquhar, JW; Stein, Y. (1960). Carbohydrate-induced and fatinduced lipaemia.Transaction Association of American Physicians, 74: 134-46.

Allain, CC; Poon, LS; Chan, CSG; Richmond, W; $\mathrm{Fu}$, PC.(1974).Enzymatic determination of total serum cholesterol. Clinical Chemistry, 20: 470-3

Austin, MA; Holkanson, JE; Edwards, KL. (1998). Hypertriglyceridemia as a cardiovascular risk factor. American Journal of Cardiology, 81: 7B$12 B$.

Ben-David, M; Duffy LK; Bowyer RT (2001).Biomarker responses in river otters experimentally exposed to oil contamination. Journal Wildlife Disease, 37 (3): 489 - 508.

Bourdoux, P; Mafuta, M; Hanson, A;Ermansa, M. (1980). Cassava toxicity: the role of linamarin. In: Role of Cassava in the Etiology of Endemic Goitre and Cretinism (Ermans, A. M.,Inbulamoko, N. M., Delange, F. \&Ahluwalia, R., eds.). International Development Research Centre, Ottawa. Pp. 15-28.

Braide,AS; Adegoke, OA;Bamigbowu, EO;Ayodele, MBO.(2011a). Effect of sugar on some heamatological parameters in albino rats fed with petroleum contaminated diet. International Journal of Applied Biological Research, 3(1):9099.

Braide,AS; Adegoke, OA;Bamigbowu, EO;(2011b). Effect of Cassava based diet on hepatic proteins in albino rats fed with crude oil contaminated diet. Journal of Applied Science and Environmental Management, 15(1):223-229.

Braide,AS; Adegoke, OA;Bamigbowu, EO; Ayodele, MBO. (2011c).Comparative effects of Sugar and Gari diets on hepatic enzymes in rats fed crude oil contaminated diet. World Journal of Environmental Pollution, 1(2):11-15.

Braide, AS; Adegoke, OA; Bamigbowu, EO. (2013).Effect of Cassava based diet on lipids concentration in albino rats fed with crude oil contaminated diet. Journal of Applied Science and Environmental Management, 17 (1): 15-19

Breimer, LH. (1990). Moleculer mechanisms of oxygen radical carcinogenesis and mutagenesis: the role of DNA base damage. Molecular Carcinogenesis 3:188-197. 
Buccolo, G; David, H. (1973).Quantitative determination of serum triglycerides by the use of Enzymes. Clinical Chemistry 19:476-482.

Chou, CC; Jasovsky, GA. (1993).Advantages of EcosorbTMprecoats in liquid sugar production.International Sugar Journal, 95 (1138):425-430.

Coppock, RW; Mostrom, MS; Khan, A;Semalula, SS. (1995): Toxicology of oil field pollutants in cattle: A review. Veterinary and Human Toxicology, 37 (6): $369-576$.

Edwards, CW.(1989).Toxicology of oil field waste hazards to livestock associated with the petroleum industry. Veterinary Clinic of North America,; 5: 363 - 374.

Ezeji, EU.,Obidua, O; Kalu, IG; Nwachukwu IN.(2009).Effect of gari diet on marker enzymes of mice liver mitochondrial. Pakistan Journal of Nutrition, 8(4):414-418.

Friedwald, TW; Fredrickson, DS; Levy, RJ.(1972). LDL cholesterol estimation.Clinical Chemistry, 18:499-501.

Glazer, AN;Nikaido, H.(1995). Microbial Biotechnology: in: Fundamentals of Applied Microbiology. $2^{\text {nd }}$ ed., New York, W.H. Freeman and Company, Pp640, ISBN 0-71-67 2608-4.

Glew, RH. (1997) Lipid Metabolism 11: pathways of metabolisms of special lipids. In Textbook of Biochemistry with Clinical Correlations Devlin TM (ed) $4^{\text {th }}$ edition. Wiley-LissIn C New York pp 415-417.

Gomez, G; Aparicho, MA;Willhite, CC.(1988). Relationship between dietary cassava cyanide levels and broiler performance.Nutrition Report International; 37:63-75.

Halliwell, B. (1994). Free radicals, antioxidants and human disease: Curiosity, cause or consequence? Lancet 334:721-724.
Knittle, JL; Ahrens, EKJ.(1964). Carbohydrate metabolism in two forms of hyperglyceridemia.Journal of Clinical Investigation, 43: 485-495.

Mckee, T;Mckee, RI.(1999).Biochemistry $2^{\text {nd }}$ Ed McGraw Hill, New York pp 135- 238.

Omoregie, E. (1998). Changes in the haematology of the Nile tilapia (Oreochromisniloticustrewavas) under the effects of crude oil. Acta. Hydrobiology, 84: 287-292.

Orisakwe, OE; Akumka, DD; Afonne, OJ; Gamaniel, $\mathrm{K}$ S.(2000).Investigation into the pharmacological basis for folkloric use of Bonny light crude oil in Nigeria.Indian Journal of Pharmacology,32: 231-34.

Parks, EJ;Hellerstein, MK. (2000). Carbohydrate induced hypertriglyceridemia: historical perspective and review of biological mechanism I. American Journal of Clinical Nutrition, 71: 412-433.

Pigeolet, E; Corbisler P; Houbion A; Lamber, D;Michiels, C.(1990). Glutathione peroxidases, superoxide dismutase and catalase inactivation by peroxides and oxygen derived free radicals. Mechanism of Ageing Development, 51:283-297.

Reaven, GM; Hill, DB; Gross, RC; Farquhar, JW.(1965).Kinetics of triglyceride turnover of very low density lipoproteins of human plasma. Journal of Clinical Investigation, 44: 1826-33.

Romero, F.J; Bosch-Morell,F; Romero, MJ;Jareno, EJ; Marine, N. (1998).Lipid peroxidation products and antioxidant in human disease. Environmental Health Perspective,106(Suppl) 5:1390-1393.

Sims, P.(1980). The metabolic activation of chemical carcinogens. British Medical Bulletin, 36: 11 18.

Souza, MF; Tome, AR; Rao, VS.(1999). Inhibition by the bioflavonoid ternation on Aflatoxin B1induced lipid peroxidation in rat liver.Journal of Pharmaceutical Pharmacology 51:125-129. 